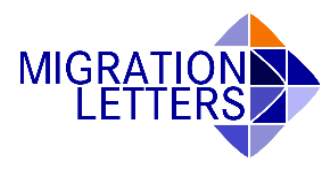

First Submitted: 6 June 2019 Accepted: 16 January 2020

DOI: https://doi.org/10.33182/ml.v17i2.804

\title{
Participatory Research: Still a One-Sided Research Agenda?
}

\author{
Derya Ozkul ${ }^{1}$
}

\begin{abstract}
Despite the prevalence of the term over the last two decades, scholars have not agreed on a definition of, or approach towards, participation, although critiques have emphasised that participation is not an equal process for all parties involved. By reviewing the literature and giving examples from fieldwork carried out in Lebanon, this article agrees with the common critique around participation and reflects over the limitations resulting from inherent power imbalances between researchers and participants and among community members. It also argues that the "glorification of methods" alone disguises the politics and the one-sided nature of participatory research and disregards the question of to what extent participants are involved in the construction of the methodology. This article suggests that-despite the pressure from funders to find out innovative methods - participatory researchers would benefit from understanding participants' own ways of conceptualising and investigating a phenomenon, in order to build their methodology. This article explores these questions, particularly in research with migrants and refugees.
\end{abstract}

Keywords: qualitative methods; participatory research; migrants; refugees; creative methods.

\section{Introduction}

Participatory methodologies have become increasingly prevalent in social research, primarily for practical and ethical reasons. On a practical level, participatory research has been used to overcome difficulties experienced during the recruitment phase of research in selecting and convincing participants to speak for the researcher. Recruitment is particularly challenging if the group concerned has limitations or reservations about communicating with outsiders. To surmount such challenges in reaching out to participants, researchers have increasingly formulated innovative participatory methods so that they can communicate with groups such as the disabled, children, or PTSD sufferers, where traditional interview techniques and surveys would fall short in understanding participants' perceptions (see, for example, Aldridge, 2014). Participatory research is also deemed appropriate in development-induced studies where researchers seek to understand residents' problems concerning future development or to learn from their local knowledge to design the project and its outcomes. This type of 'development-induced participation', or what Hickey and Mohan (2005) call the 'populist/participation in development' approach, focuses on partnership only for specific projects (Cooke and Kothari, 2001), rather than for a more extensive transformation of structural inequalities.

In addition to the practical requirements, there has been growing concern about the ethical challenges in research. Traditional methods of 'extracting data' from humans have been subject to increasing criticism by both scholars and funders, and the impact on participants has been identified

\footnotetext{
${ }^{1}$ Dearya Ozkul, Refugee Studies Centre, Department of International Development, University of Oxford, 3 Mansfield Road, Oxford OX1 3TB, United Kingdom. Email: derya.ozkul@qeh.ox.ac.uk.
} 


\section{Participatory Research: Still a One-Sided Research Agenda?}

as needing greater discussion. Research in which participants follow instructions and answer the researcher's questions in a clinical manner has been found not only to be unsatisfactory in understanding perceptions but also undemocratic. In general, participatory research is based on the assumption that participatory methods can enable marginalised groups to speak out, transforming social and power relationships in research. Calls for democratic co-construction of knowledge are also extended to international collaborative research projects, where concepts and theories can be built up from local contexts (Gaventa \& Bivens, 2014).

Despite the prevalence of the term over the last two decades, scholars have not agreed on a standard definition of, or approach towards, participation, although critiques have emphasised that participation is not an equal process for all parties involved. This article gives an overview of the current debates: in general, the 'participatory turn' in scholarly literature is based on an optimistic assumption that the use of participatory methods would enable knowledge production to become more democratic. Landau (2012) points out that partnerships, even between scholars in the Global North and South, are not equal and southern scholars are further impelled to do the work that fits the Northern scholars' priorities. Other scholars criticise 'democratic piety' (Little, 2008) and claim that uncritical approaches to participation can strengthen local power differentials.

By reviewing the literature and giving examples from fieldwork carried out in Lebanon in 2019 , I agree with this common critique and point out another dimension. This article argues that the glorification of methods alone disguises the political and one-sided nature of participatory research and disregards the question of whether the chosen methods are participants' methods. Instead of focusing on discovering innovative methods alone, participatory research may benefit from working with participants' own practices to find out about a phenomenon. This article explores this dimension, particularly in research with migrants and refugees. It also explores the limitations by looking into the inherent power imbalances between researchers and participants, how these relationships impact the political economy of research and the practical difficulties in achieving participation in all stages of research.

\section{Scholarly Debates: Conceptualising Participation}

Scholars coming from diverse theoretical traditions conceptualise participation differently and, therefore, also generate knowledge in varied ways. Those who have a pragmatic view of participatory research aim to solve problems in particular localities or communities. This strand of literature relates mostly to community-driven participatory research. Concerned with the coanalysis of research findings, that is, with knowledge production, Pohl et al. (2010, p. 267) argue that 'sustainable development requires production of knowledge that strikes a balance between scientific and other forms of knowledge'. Reviewing the literature, Pohl et al. (2010) find that the production of knowledge takes place in two different ways. The first type occurs through 'boundary organisations', that is, through organisations that are distinct from both academic and non-academic worlds and mediate between the two. In the second type, Pohl et al. (2010, p. 269) find that 'knowledge production takes place at the intersection of the realms of science and non-science the agora'. Although scientists and non-scientists can both contribute equally to the agora, this strand of literature does not question who has the power to initiate and build the conceptual framework of research.

In contrast, those who work with critical theory consider the literature oriented towards problem-solving as a way of continuing the system as it is, with only minor changes. Instead, they 
argue that critical theory helps participants to develop a critical lens regarding their conditions so that they themselves are able to transform those conditions. In other words, this second strand helps in questioning the broader structures that limit contributions made by groups and individuals. Critical theorists consider knowledge production to be a means of deconstructing existing dominant scholarly knowledge by giving space to participants' knowledge. This view has been prevalent, especially in participatory research conducted with indigenous communities that attempts to decolonise the prevailing theories of the Global North (Christensen, 2012; Koster, Baccar, \& Lemelin, 2012; Leeuw, Cameron, \& Greenwood, 2012). The aim of participatory research in this strand is to achieve 'inclusivity, multiple perspectives and ways of knowing', while acknowledging that 'research is not value free' (Koster et al., 2012, p. 195). While linking the two worlds, De Sousa Santos (2005) points to the importance of interpretation between fragments of knowledge and the practices of local organisations concerned with vernacular traditions and objectives, and international or transnational organisations that seek to make more extensive changes.

Some indigenous scholars also criticise researchers working with critical theory. Coombes (2012, pp. 290-291), for instance, argues that 'collaborative research is oxymoronic to the extent that, if successful, it undermines its raison d'être by establishing any need for outsiders', pointing out that normalisation of community-based participatory research limits its agenda and, moreover, its researchers' righteousness blinkers them to their 'reproduction of colonial Othering'. More importantly, even in the best-case scenario where the entire research process is based on a collaborative understanding, 'the need for exogenous researchers is unquestioned, thereby limiting any prospect of transitioning knowledge production to Indigenous communities' (Coombes, 2012, p. 291), a point which I will also explore below.

In addition to different theoretical approaches, scholars conceptualise 'participation' based on typologies and locate different degrees of participation on a spectrum. Among these, Arnstein's (1969) pioneering article 'Ladder of Citizen Participation' indicates that not all engagement is of equal nature, and that 'community participation' is 'an empty and frustrating process' for most members, because labelling a study as participatory would 'allow the power holders to claim that all sides were considered' while, in fact, no changes were made for the community. Therefore, Arnstein (1969) suggests locating participation on a ladder consisting of non-participation, the degree of tokenism, and the degree of citizen power. Other scholars develop this model by adding additional dimensions. Pretty (1995), for instance, suggests conceptualising participation solely according to degrees of activity and passivity in research. Wilcox's framework (2004) adds two further aspects to Arnstein's ladder model, which are the different phases of participation and diverse interests at various stages. While all of these critical scholars demonstrate that the term 'participatory research' alone is limited in understanding the extent to which participants are involved in research, they refrain from criticising the unilateral use of participatory methods. The next section goes into more detail about this inherently unequal relationship.

\section{The Glorification of Methods}

The emphasis on participatory methods in the literature helps the reader to question commonly used techniques such as interviews, and to come up with new, innovative ways; however, this emphasis may also disguise the one-sided nature of participatory methods. The researcher is still the one who 'invites' participants to work together with him/her and participate in the research placing the researcher in a superior position from the beginning, even if ideally all participants are equally involved in all phases of research. Also, participatory research still allows the researcher to 


\section{Participatory Research: Still a One-Sided Research Agenda?}

decide 'how to empower' the communities concerned - although empowerment projects often do not aim to avoid power relationships, but rather to transform the participants into responsible selfgoverning individuals (Triantafillou \& Nielsen, 2001). In research with refugees, who counts as a 'participant' is an even more difficult question, as participants may include documented and undocumented migrants, gatekeepers, interviewers, interpreters, and the research assistants that make the research project possible (Doná, 2007).

The glorification of methods used more generally in social sciences, insisted on by both funders and scholars, may push researchers to come up with new 'innovative methods', or as they are sometimes referred in the literature, 'creative methods' (Wiles, Crow, \& Pain, 2011). These methods may involve arts-based techniques, including theatre, photography, video recording, diary writing, drawing, using software tools, among others (Castleden, Garvin, \& First Nation, 2008; Erel, Reynolds, \& Kaptani, 2017; Nash \& Moore, 2018; Parry, 2015). Some researchers may also employ traditional methods, such as surveys, interviews and focus groups, as long as they are participatory in their approach to data collection (Letiecq \& Schmalzbauer, 2012; Wieland et al., 2012). While both types of methods can enable research participants to be directly involved in the research process, the former type has the potential to facilitate research data to be gathered in new forms and to provide results for visually appealing presentations; and, most importantly, to reveal emotionally involved findings. However, too much emphasis on methods risks of neglecting the essence of participatory research, that is transforming the power imbalances in a given context, and risks being celebratory of its own methods alone - perhaps because participatory research was, rightfully, a breakthrough in academic research towards a more democratic way of doing research. Moreover, too much emphasis on methods fails to consider whether participatory research continues as a onesided process that hides the unequal relationships between the researcher, interlocutors (if any), and participants.

Accordingly, the glorification of methods alone runs the risk that the researcher will use 'creative methods' without assessing whether those methods are the participants' usual methods. Creative methods used in participatory research are often found to be ground-breaking, either because they were not used previously in scholarly literature, or because they fit the aesthetic needs of some readers. However, these methods can also be unsettling for participants if the latter do not use them to express their emotions. For instance, photography, video or theatre performances may help to reveal complicated feelings, yet may also create more conflict among participants - because the chosen method is not only foreign to their experience of emancipation but may also further change community relations or the understanding of expression. In research with refugees, for instance, photography or photo-voice has become popular, partly because it reveals images of refugees' previously unknown daily practices to outsiders, but also because it serves the aesthetic priorities of a particular audience with a fondness for that specific type of art.

It will be apparent to the reader that participatory research may not necessarily be the most democratic way of doing research; instead, it may still constitute an unequal relationship between the researcher and participants. There seems to be a grave error, therefore, if researchers prioritise or select specific methods for participants. If one wishes to find out about a phenomenon that the participants themselves are interested in understanding, in the first place, one must employ techniques that the participants themselves would use. The next section will explore the limitations in achieving an equal relationship in research with migrants and refugees. 


\section{Limitations in Participatory Research: Power Imbalances and Practical Difficulties}

It is difficult to move beyond the inherently unequal relationship between researchers and participants, as can be observed in questions around visibility, distinct ways of conceptualising the issues at stake, different values attached to those concepts and, finally, varying degrees of power in accessing individuals' living space.

Power imbalances may stem from the vastly different ways researchers and participants may conceptualise the issues at stake. Some concepts may not mean anything distinctive to either researchers or participants, while other concepts may not exist in the other's language to start with, signifying that the two parties may not be able to conceptualise 'equally' in research settings. For example, the word 'vulnerability' has recently become a popular term among UNHCR and other English-speaking international humanitarian actors. In Lebanon, for instance, assessments for aid have been conducted among 'vulnerable refugee populations', yet the word 'vulnerable' cannot be translated directly into the refugees' native language Arabic (Ho Thanh, 2019, p. 27). Besides the fact that refugees do not have access to the selection criteria used in these vulnerability assessments, they do not conceptualise the term in the same way as humanitarian actors do, simply because the word does not exist for them in its exact meaning. Similarly, the research questions preferred by participants (e.g., how to have access to money, food, and health, or how to legalise their residences) may not translate as the same questions for researchers. That is because, like concepts, research questions have different values for migrants and refugees from those held by academic researchers.

The question of the unequal relationship between researchers and participants is especially pertinent in cases where participants lack legal status to reside in research place. Accordingly, participatory methods may pose significant risks if their personal identity is revealed in participatory research using visual or audio techniques. There needs to be greater scrutiny especially in written and visual publications about the use of such material, which in the long term may jeopardise participants' security. Mediatisation of personal pictures or documents, such as ID cards or specific permits may serve researchers' interests, but not in the same way as participants' interests.

Similarly, power imbalances reveal themselves while accessing someone's personal living space. Researchers, especially from well-known Western universities, can often gain access to participants' living or working space with relative ease, depending on the nature of the research. They may need to obtain 'informed consent' from participants, as most Northern universities require this $^{2}$, yet they are often able to ask for that consent in participants' own living space - in other words, after they have already met them in their own space. On the other hand, if participants wish to enter researchers' living or working space, they risk being rejected before they can even reach them. In other words, the question of who is able to get access to someone else's space has inherently political and ethical implications (Boser, 2006; Maiter, Simich, Jacobson, \& Wise, 2008; Reason \& Bradbury, 2008). The fact that researchers are able to investigate the area where they have the legal right to stay also places them on a higher level in the relationship. When they arrive at the research setting and start asking about the study, they may already be coercing participants even if it does not appear to be visibly evident. Moreover, as many migrant and refugee communities have lamented, 'helicopter projects' or 'drive-by research' (Horowitz, Robinson, \& Seifer, 2009) in a particular area or with a specific population have resulted in 'research fatigue' which hinders future research (Clark, 2008) or transmutes the research to entrepreneurial activity.

${ }^{2}$ See (Bell, 2014) for a critique of the requirement to have 'informed consent' in academic research. 


\section{Participatory Research: Still a One-Sided Research Agenda?}

The transformation of research into entrepreneurial activity is already evident in highly researched countries like Lebanon - either through private consultancy companies undertaking such research for researchers who may not have the time to engage with participants or through individuals whose job it is to recruit people for researchers. In Lebanon, for instance, where since 2012, numerous research projects have been carried out mainly with Syrian refugees, some camp or community leaders have started working for NGOs and researchers as recruiters. This role is different from the traditional definition of 'gatekeeper' in research in the sense that, unlike a traditional gatekeeper who works voluntarily and free of charge, these interlocutor recruiters are often paid. For example, a recruiter who works for an NGO in Lebanon earns around 500 USD per month to recruit participants, as compensation for the time he or she spends in the field connecting with and convincing participants, as well as with their own contacts. The use of interlocutors contributes to the development of the political economy of research. Paying interlocutors but not participants (or paying them at different rates because of their diverse skills) strengthens the already existing power inequalities among community members.

One can argue that the recent growth in emphasis on having a practical 'impact', which has become established, especially in Anglo-Saxon universities, may help to endorse research gains. Having an 'impact' has become an increasing requirement for funders, some of whom have created specific schemes for partnerships between academia and industry. For example, the Australian Research Council has initiated Linkage Projects, where researchers are required to work with industry partners such as community organisations, and to gain from the research according to their own needs. ${ }^{3}$ Such initiatives by funding bodies can help with financing participatory research projects, from the outset of research design to the analytical phases.

However, there are also practical challenges related to the restrictions imposed by the funders and everyday difficulties in the research setting. Funding applications usually need to be prepared to a very tight schedule. Even if researchers and participants decide on the essential issues to be studied well in advance, funders' priorities and expectations change every year depending on various factors, leaving researchers and participants with very little time to corroborate their ideas (Aldridge, 2014, p. 116; Israel, Schulz, Parker, \& Becker, 1998). Moreover, if the research questions and methods are not sufficiently clarified, funders may not provide funding in the first place. Most funders require researchers, at the application stage, to demonstrate what the exact research questions will be, the methods that will be employed, and how the study will contribute to academic literature. Participatory research, though, has to use grounded approaches, where the questions and methods are clarified during research with participants, instead of dictating research questions that are important only for researchers. However, funders often refrain from studies where the problems and methods are not fully articulated at the application stage.

In addition, the research setting itself may not be convenient for participatory research. Even if the participatory research is designed as a pilot study with refugees in some of the informal settlements, once the study starts, they may not be able to continue the research for various reasons. For instance, in Lebanon, the local authorities, including national and municipal police or the host community, frequently harass migrants and refugees and threaten them with eviction. In these

\footnotetext{
${ }^{3}$ See more about Linkage Projects at https://www.arc.gov.au/grants/linkage-program/linkage-projects. One such study, entitled 'Settlement Outcomes of Syrian-conflict Refugee Families in Australia', conducted by three universities in Sydney, looks at settlement outcomes through partnerships between academics and settlement service providers in New South Wales, Victoria and Queensland. This project aims to provide theories about settlement outcomes in various areas of academic inquiry and improve the actual services of the service providers.
} 
circumstances, participants may not be able to work with the researcher (or use the methods they first envisaged) any more, due to lack of privacy, harassment by neighbours, or frequent curfews imposed by the municipalities, amongst others (Human Rights Watch, 2018). Issues that are important for refugees may also change quickly, especially in places where they lack secure domiciliary status. For example, in my research with refugees in Lebanon, the topics that mattered for them changed continuously due to frequent pronouncements issued by the General Directorate of General Security, the administrative body responsible for monitoring foreigners in Lebanon. Whereas, at the beginning of my research, the authorities generally avoided deporting undocumented Syrians from Lebanon due to their respect for the principle of non-refoulement, by mid-2019 removal had become a significant threat for many refugees. General Security introduced stricter controls over work permits, resulting in those without work permits losing their jobs or accepting lower salaries. As such, in places where policy changes are very frequent, undocumented migrants and refugees are under constant pressure to follow the news and may be uninterested in participating in research - which often takes a long time. In these circumstances, it is even harder for researchers and participants to work together to achieve major structural changes.

\section{Conclusion}

I started this article with a question about whether participatory research is still a one-sided research agenda, similar to those forms of research that it positions itself against. I have explored the continuing practical and ethical problems in participatory research, in this article specifically with migrants and refugees. The critiques and limitations that I have mentioned should not undermine the value of participatory methodologies, which have rightfully unsettled the traditional methods of 'data collection' where researchers 'extract data' from interviewees. Participatory research, and research using creative methods within this framework, has great potential to reach out to more people than orthodox research, to reveal emotionally involved findings and to initiate new thought-provoking processes.

However, I have also raised two major cautionary points. First, I have argued that too much emphasis on methods alone risks neglecting the objectives of participatory research that is understanding and transforming the power structures in a given context in line with needs designated by participants. Second, the glorification of methods may also push researchers to innovate and propose methods without thoroughly reflecting on their implications for participants. Similar to those 'extracting data' from interviewees through traditional methods, I have suggested those who use creative methods must refrain from encouraging or imposing specific methods on participants. It is essential to reflect on the question of which methods benefit (or harm) whose interests and needs. These two points can be different risks related to the same phenomenon, which is giving too much emphasis on methods at risk of the aims of the research. Ultimately, answering these questions may help us develop the potential of participatory research so that it becomes rooted in a dynamic and multifaceted relationship.

\section{References}

Aldridge, J. (2014). Working with vulnerable groups in social research: dilemmas by default and design. Qualitative Research, 14(1), 112-130. doi:10.1177/1468794112455041

Arnstein, S. R. (1969). A Ladder Of Citizen Participation. Journal of the American Institute of Planners, 35(4), $216-224$. doi:10.1080/01944366908977225 


\section{Participatory Research: Still a One-Sided Research Agenda?}

Bell, K. (2014). Resisting Commensurability: Against Informed Consent as an Anthropological Virtue. American Anthropologist, 116(3), 511-522. doi:10.1111/aman.12122

Boser, S. (2006). Ethics and power in community-campus partnerships for research. Action Research, 4(1), 9-21. doi:10.1177/1476750306060538

Castleden, H., Garvin, T., \& First Nation, H.-a.-a. (2008). Modifying Photovoice for community-based participatory Indigenous research. Social Science \& Medicine, 66(6), 1393-1405. doi: /10.1016/j.socscimed.2007.11.030

Christensen, J. (2012). Telling stories: Exploring research storytelling as a meaningful approach to knowledge mobilisation with Indigenous research collaborators and diverse audiences in community-based participatory research. The Canadian Geographer / Le Géographe Canadien, 56(2), 231-242. doi:10.1111/j.15410064.2012.00417.x

Clark, T. (2008). 'We're Over-Researched Here!': Exploring Accounts of Research Fatigue within Qualitative Research Engagements. Sociology, 42(5), 953-970.

Coombes, B. (2012). Collaboration: Inter-subjectivity or radical pedagogy? The Canadian Geographer / Le Géographe Canadien, 56(2), 290-291. doi:10.1111/j.1541-0064.2012.00429.x

Cooke, B. and Kothari, U. (2011). Participation: the New Tyranny? London: Zed Books.

De Sousa Santos, B. (2005). The Future of the World Social Forum: The work of translation. Development, 48(2), 15-22.

Doná, G. (2007). The Microphysics of Participation in Refugee Research. Journal of Refugee Studies, 20(2), 210-229. doi: $10.1093 / \mathrm{jrs} / \mathrm{fem} 013$

Erel, U., Reynolds, T., \& Kaptani, E. (2017). Participatory theatre for transformative social research. Qualitative Research, 17(3), 302-312. doi:10.1177/1468794117696029

Gaventa, J., \& Bivens, F. (2014). Co-constructing Democratic Knowledge for Social Justice: Lessons from an International Research Collaboration. In J. Shefner, H. F. Dahms, R. E. Jones, \& A. Jalata (Eds.), Social Justice and the University: Globalisation, Human Rights, and the Future of Democracy (pp. 149-174). London: Palgrave Macmillan UK.

Hickey, S., \& Mohan, G. (2005). Relocating Participation within a Radical Politics of Development. Development and Change, 36(2), 237-262. doi:10.1111/j.0012-155X.2005.00410.x

Ho Thanh, D. (2019). "All We Know Is That We're Refugees": Vulnerability, Knowledge, and UNHCR Assistance to Syrian Refugees in Lebanon. (MPhil), University of Oxford, Oxford.

Horowitz, C. R., Robinson, M., \& Seifer, S. (2009). Community-based participatory research from the margin to the mainstream: are researchers prepared? Circulation, 119(19), 2633-2642. doi:10.1161/CIRCULATIONAHA. 107.729863

Human Rights Watch. (2018). "Our Homes Are Not for Strangers": Mass Evictions of Syrian Refugees by Lebanese Municipalities. Retrieved from https://www.hrw.org/report/2018/04/20/our-homes-are-not-strangers/mass-evictionssyrian-refugees-lebanese-municipalities

Israel, B., Schulz, A., Parker, E., \& Becker, A. (1998). Review of community-based research: assessing partnership approaches to improve public health. Annu Rev Public Health, 19, 173-202.

Koster, R., Baccar, K., \& Lemelin, R. H. (2012). Moving from research ON, to research WITH and FOR Indigenous communities: A critical reflection on community-based participatory research. The Canadian Geographer / Le Géographe canadien, 56(2), 195-210. doi:10.1111/j.1541-0064.2012.00428.x

Landau, L. B. (2012). Communities of Knowledge or Tyrannies of Partnership: Reflections on North-South Research Networks and the Dual Imperative. Journal of Refugee Studies, 25(4), 555-570. doi:10.1093/jrs/fes005

Leeuw, S. d., Cameron, E. S., \& Greenwood, M. L. (2012). Participatory and community-based research, Indigenous geographies, and the spaces of friendship: A critical engagement. The Canadian Geographer / Le Géographe canadien, 56(2), 180-194. doi:10.1111/j.1541-0064.2012.00434.x

Letiecq, B., \& Schmalzbauer, L. (2012). Community-based participatory research with Mexican migrants in a new rural destination: A good fit? Action Research, 10(3), 244-259. doi:10.1177/1476750312443571

Little, A. (2008). Democratic Piety: Complexity, Conflict and Violence. Edinburgh: Edinburgh University Press.

Maiter, S., Simich, L., Jacobson, N., \& Wise, J. (2008). Reciprocity: An ethic for community-based participatory action research. Action Research, 6(3), 305-325. doi:10.1177/1476750307083720

Nash, M., \& Moore, R. (2018). Exploring research relationships and other ethical challenges of participatory visual research in remote environments. Journal of Sociology, O(0), 1-20. doi:10.1177/1440783318802982

Parry, B. (2015). Arts-Based Approaches to Research with Children: Living with Mess. In E. Stirling \& D. Yamada-Rice (Eds.), Visual Methods with Children and Young People: Academics and Visual Industries in Dialogue (pp. 89-98). London: Palgrave Macmillan UK.

Pohl, C., Rist, S., Zimmermann, A., Fry, P., Gurung, G. S., Schneider, F., Ifejika Speranza, C., Kiteme, B., Boillat, S., Serrano, E., Hirsch Hadorn, G., Wiesmann, U. (2010). Researchers' roles in knowledge co-production: experience 
from sustainability research in Kenya, Switzerland, Bolivia and Nepal. Science and Public Policy, 37(4), 267-281. doi:10.3152/030234210x496628

Reason, P., \& Bradbury, H. (2008). Handbook of action research: Participative inquiry and practice. Thousand Oaks, CA: SAGE.

Triantafillou, P., \& Nielsen, M. R. (2001). Policing empowerment: the making of capable subjects. History of the Human Sciences, 14(2), 63-86. doi:10.1177/09526950122120961

Wieland, M. L., Weis, J. A., Palmer, T., Goodson, M., Loth, S., Omer, F., Abbenyi, A., Krucker, K., Edens, K., Sia, I. G. (2012). Physical Activity and Nutrition among Immigrant and Refugee Women: A Community-Based Participatory Research Approach. Women's Health Issues, 22(2), e225-e232. doi: 10.1016/j.whi.2011.10.002

Wilcox, D. (2004). Partnerships and participation: Framework for Participation. Retrieved from http://www.partnerships.org.uk/guide/frame.htm

Wiles, R., Crow, G., \& Pain, H. (2011). Innovation in qualitative research methods: a narrative review. Qualitative Research, 11(5), 587-604. doi:10.1177/1468794111413227. 
MIGRATION LEIIERS SERIES BY TRANSNATIONAL PRESS LONDON

Reader in Qualitative Methods in Migration Research

Edited by lbrahim SIRKECI, Theodoros IOSIFIDES, Carla DETONA, Annalisa FRISINA

This edited collection of articles published in Migration Letters were selected to reflect on methodological challenges faced were selected to reflect on methodological challenges faced yydies on migation. Beginin with papers focusing on studies on migration. Beginning with papers focusing on brodder discussions of methodological issues and some options avalable to researchers, the latier half of the bock expiones the cases.

The chapters included in this book was originally published in regular issues and two special issues of Migration Letters journo from 2009 onwards. These special issues were guest edited by Theodoros lositidis and Deborah Sporton in 2009 and by Carla De Tona, Annalisa Frisina and Deianira Ganga in 2010. We have Degrouped and crdered these siudies to enhance the fiow and fransition in the book. The first six chapters look into more general issues and debales in migralion research

on alternative qualitative methodologies and then the final six
chapters focus on narratives and challenges of the narrative methodology appled in migralion studies.
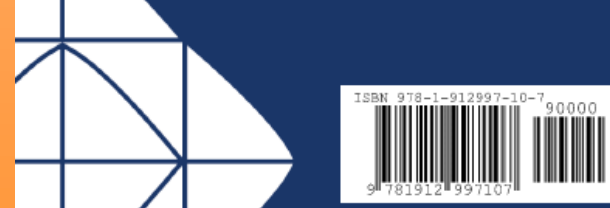

STRANSNATIONAL PRESS
READER IN QUALITATIVE METHODS IN MIGRATION RESEARCH

Edited by

Ibrahim SIRKECI

Theodoros IOSIFIDES

Carla DETONA

Annalisa FRISINA

Please visit

www.tplondon.com

...fostering research, widening reach... 